\title{
Reflexões sobre a dimensão do cuidado na busca da justiça curricular das escolas do campo do município de Humaitá (AM)
}

\author{
Zilda Gláucia Elias Franco ${ }^{1}$ \\ 1 Universidade Federal do Amazonas - UFAM. Instituto de Educação, Agricultura e Ambiente (IEAA). Campus Vale do Rio \\ Madeira. Rua 29 de Agosto 786, Centro. Humaitá-AM. Brasil. \\ Autor para correspondência/Author for correspondence: zildaglaucia@hotmail.com
}

\begin{abstract}
RESUMO. A justiça curricular, com suas três dimensões conhecimento, convivência e cuidado -, define que o currículo atenda a todas as necessidades dos envolvidos e os forme como pessoas solidárias e corresponsáveis na construção de uma sociedade mais justa. Assim sendo, o objetivo deste artigo, recorte de uma pesquisa de doutorado, foi identificar, na realidade das escolas do campo do município de Humaitá, Amazonas, os limites e as possibilidades no atendimento às crianças da região, tendo como parâmetro a dimensão do cuidado na busca da justiça curricular. A pesquisa participativa, utilizando-se de pesquisa de campo, análise documental, entrevistas, momentos de reflexão-ação e de escuta sensível (Barbier, 2007), com gestores, professores, merendeiras, pais e alunos, em sua fase exploratória, resultou no levantamento das dificuldades encontradas pelos participantes quanto ao atendimento da Educação do Campo: calendário escolar, transporte e merenda escolar. Os resultados apontam para a grande distância entre o que está escrito e a prática curricular, levando à injustiça curricular. Faz-se necessário, assim, refletir sobre a concepção da justiça curricular, em especial a dimensão do cuidado, pois um ambiente democrático e acolhedor das diferenças ajuda a garantir e a consolidar a formação solidária e modificar o processo de construção do conhecimento.
\end{abstract}

Palavras-chave: Justiça Curricular, Cuidado, Escolas do Campo. 


\title{
Reflections on the dimension of care in the search for curricular justice in the field schools of the municipality of Humaitá (AM)
}

\begin{abstract}
Curricular justice, with its three dimensions knowledge, coexistence and care -, defines that the curriculum meets all the needs of those involved and educates them as supportive and co-responsible people in the construction of a more just society. Therefore, the objective of this paper, a cutoff of a doctoral research, was to identify, in the reality of the field schools of the municipality of Humaitá, Amazonas, the limits and the possibilities in the care of the children of the region, having as parameter the dimension of care in the pursuit of curricular justice. Participatory research, using field research, documentary analysis, interviews, moments of reflection-action and sensitive listening (Barbier, 2007), with managers, teachers, school cooks, parents and students, in their exploratory phase, resulted in the survey of the difficulties encountered by the participants regarding the attendance of Rural Education: school calendar, transportation and school meals. The results point to the great distance between what is written and the curricular practice, leading to curricular injustice. It is therefore necessary to reflect on the conception of curricular justice, especially the dimension of care, since a democratic and welcoming environment of differences helps to guarantee and consolidate solidarity education and modify the process of knowledge construction.
\end{abstract}

Keywords: Curricular Justice, Care, Rural Schools. 


\section{Reflexiones sobre la dimensión del cuidado en la búsqueda de la justicia curricular de las escuelas unitarias del municipio de Humaitá (Amazonas, Brasil)}

RESUMEN. La justicia curricular, con sus tres dimensiones conocimiento, convivencia y cuidado -, define que el currículo atienda a todas las necesidades de los involucrados y los forme como personas solidarias y corresponsables en la construcción de una sociedad más equitativa. El objetivo de este artículo, el cual es un recorte de una investigación llevada durante el doctorado, fue identificar, en la realidad de las escuelas unitarias del municipio de Humaitá, Amazonas, los límites y las posibilidades en la atención a los niños de la región, teniendo como parámetro la dimensión del cuidado en la búsqueda de la igualdad curricular. En este estudio se utilizó una metodología investigación participativa, llevada a cabo mediante el trabajo de campo, el análisis documental, las entrevistas, los momentos de reflexión-acción y de la escucha sensible (Barbier, 2007), con gestores, profesores, monitores del comedor escolar, padres y alumnos, en su fase exploratoria, resultó en el levantamiento de las dificultades encontradas por los participantes en cuanto a la atención de la Educación del Campo: calendario escolar, transporte y merienda escolar. Los resultados apuntan a la gran distancia entre lo que está escrito y la práctica curricular, obteniendo como resultado lo que se denomina como injusticia curricular. Este hecho, hace que sea necesario reflexionar sobre la concepción de dicha justicia curricular, en especial la dimensión del cuidado, debido a que un ambiente democrático y acogedor de las diferencias ayuda a garantizar y consolidar la formación solidaria y modificar el proceso de construcción del proceso de enseñanza aprendizaje.

Palabras clave: Justicia Curricular, Cuidado, Escuelas Rurales. 


\section{Introdução}

Este texto traz um recorte do resultado da pesquisa de Doutorado intitulada Um olhar sobre as escolas localizadas no campo do Município de Humaitá (Sul do Amazonas): em busca da justiça curricular (Franco, 2018), que se insere no âmbito do Grupo de Educação e Pesquisa em Justiça Curricular (GEPEJUC), do Programa de PósGraduação da Pontifícia Universidade Católica de São Paulo (PUC-SP), que desenvolve, no momento, uma investigação sob o título $A$ justiça curricular no século XXI, as políticas e os sujeitos do currículo.

A pesquisa apresentada aqui pretende identificar, na realidade das escolas do campo do município de Humaitá, os seus limites e as suas possibilidades no atendimento às crianças da região, tendo como parâmetro a dimensão do cuidado na busca da justiça curricular. A justiça curricular define que o currículo exercido atenda a todas as necessidades dos envolvidos e os forme como pessoas humanizadas (Freire, 1983). Se o processo educativo não contempla as necessidades dos seus sujeitos, o currículo não cumpre a sua função social. Um currículo escolar em busca da justiça amplamente compreendida não poderá prescindir de políticas públicas pautadas por direitos e da articulação dessas políticas com práticas curriculares. Além disso, a concepção de justiça curricular entende a escola como uma instituição cujos objetivos vão além da instrução. O seu compromisso com a construção da dignidade humana, com o cuidado, com a proteção dos sujeitos de forma coletiva é, portanto, fundamental.

O cuidado é compreendido como o zelo que se tem para garantir as condições para que cada educando e educador disponha de possibilidades para construir a sua formação. Para Severino (2012, p. 81), "a educação se expressa como cuidado do sujeito em sua subjetividade". Sem ele não há como obter/construir/proporcionar a formação dos alunos e dos professores que a escola pode e deve oferecer. Do cuidado da escola com todos os sujeitos participantes da comunidade, entendida como ausência de esquecimento, de reconhecimento, a preocupação e a solicitude pelos outros, ética em benefício de quem está em desvantagem (Estêvão, 2004).

Este estudo optou pela abordagem metodológica qualitativa. A investigação qualitativa "é rica em dados descritos, é aberta e flexível e foca a realidade de forma complexa e contextualizada". (Lüdke \& André, 1986, p. 18). Para a construção de dados, utilizou-se a pesquisa 
participativa e a pesquisa exploratória com o objetivo de "descobrir o campo de pesquisa, os interessados e suas expectativas e estabelecer um primeiro levantamento (ou diagnóstico) da situação, dos problemas prioritários e de eventuais ações". (Thiollent, 2011, p. 56). As atividades foram desenvolvidas com a coordenação da Educação do Campo da Secretaria Municipal de Educação do município de Humaitá (AM), com gestores, professores, merendeiras, pais, alunos, além de observações, de escutas realizadas em campo e de momentos de reflexão-ação (11 encontros na área urbana) que caracterizaram a investigação, juntamente à fundamentação teórica.

Assim, este texto visa trazer algumas reflexões acerca da dimensão do cuidado, um dos elementos da justiça curricular, com as escolas localizadas no campo no município de Humaitá. Para tanto, ele está dividido em quatro tópicos. No primeiro, “A justiça curricular", são abordadas as definições da justiça curricular e suas dimensões. No segundo, “O cenário da educação nas escolas do campo no Município de Humaitá (AM)”, apresentamse alguns dados recolhidos. O terceiro item, o "Atendimento às necessidades da região", destaca os dados levantados pela pesquisa com base na investigação; e, por fim, as "Considerações finais" referentes à temática.

\section{A justiça curricular}

No decorrer do século XX, ocorreu a Declaração Universal dos Direitos Humanos das Nações Unidas (1948), e a tese positivista passou a sofrer críticas. Nesse contexto, no Brasil, destacam-se as ideias de Miguel Reale, o qual acredita que a liberdade e a solidariedade são valores essenciais que precisam existir para que se desfrute da justiça.

Assim, a humanidade, em sua história recente, escolheu a escolarização como forma coletiva institucional de preparar as suas gerações futuras. Cada dia, com mais complexidade, os sistemas escolares de todo o mundo demandam reflexões e ações que busquem a formação de uma população constantemente em crescimento e em movimento. Nesse sentido, sem desconsiderar os avanços democráticos em relação à educação escolar do início do século XXI, expressos pela busca da universalização, pelas políticas afirmativas e de promoção de igualdades, constata-se que ainda se tem muito o que fazer na direção da construção de um currículo que contemple a justiça social e a igualdade de direitos e de deveres. 
"Preparar as gerações futuras" não é uma expressão sem intencionalidade. Valores diversos norteiam essa ação da formação a depender dos interesses em jogo, o que quer dizer que essa discussão não se faz sem debates explicitadores dessas intencionalidades, pois "a educação é processo social, atuando através das relações sociais, nas quais o 'quanto' não pode ser separado do 'quê'”. (Connell, 1995, p. 13). De acordo com o pesquisador, é preciso encontrar diferentes respostas educativas à diversidade intensa da sociedade e das escolas, de modo a entender que há um vínculo inevitável entre distribuição e conteúdo e que a justiça distributiva precisa do conceito da justiça curricular, a fim de afirmar a equidade esperada. O currículo, portanto, deve ser modificado, como propósito de refletir as formas pelas quais a diferença é produzida por relações sociais.

Para os partidários de uma educação escolar democrática e solidária, que vise a formação de gerações futuras cidadãs, trata-se de buscar formas de garantir uma educação escolar de qualidade social por meio de um currículo pautado no conceito e na prática da justiça curricular. Esta, para ser efetivada, carece de avançar na seleção e na organização do conhecimento do currículo por meio de uma construção nas bases sociais e práticas com os quais esteja envolvida. Nesse processo, três princípios devem ser observados: 1 - interesses dos grupos com menor vantagem; 2 participação e escolarização comum; e 3 produção de igualdade (Connell, 1995). "O critério da justiça curricular significa a tendência de uma estratégia educacional para produzir mais igualdade no conjunto global das relações sociais às quais 0 sistema educacional está vinculado". (Connell, 1995, p. 31).

Dessa forma, a justiça curricular é um conceito e uma prática cotidiana urgente e necessária a ser buscada. Torres Santomé afirma que:

A justiça curricular é o resultado da análise do currículo que é elaborado, colocado em ação, avaliado e investigado levando em consideração o grau em que tudo aquilo que é decidido e feito em sala de aula respeita e atende às necessidades e urgências de todos os grupos sociais; lhes ajuda a ver, analisar, compreender e julgar a si próprios como pessoas éticas, solidárias, colaborativas e corresponsáveis por um projeto de intervenção sociopolítica mais amplo destinado a construir um mundo mais humano, justo e democrático. (Torres Santomé, 2013, p. 9).

O currículo escolar é comprometido com a sociedade que se deseja e se busca, e nunca é neutro. A história do currículo mostra que ele sempre esteve vinculado a interesses e a formas de organização da sociedade (Goodson, 1997; Apple, 1989). 
Ações pautadas pelo conceito justiça curricular são intencionadas pelas várias formas de superação de desigualdades; em outras palavras, são ações que buscam a justiça e a igualdade - amplamente consideradas - por meio do currículo escolar. Nesse sentido, toma-se o currículo escolar como elemento importante a ser considerado na promoção social de alunos e de suas famílias.

A população brasileira vive sob um estado que considera legalmente que crianças e adolescentes são seres portadores de direitos. Esse patamar - o dos direitos legais - é o ponto de partida para a busca de ações e de condições que garantam a efetividade da igualdade. Tratase, portanto, de considerar a necessidade de construir um currículo sempre revisto e pensado, inserido criticamente na moldura das determinações sociais, e que esteja sempre pronto a repensar o sentido das ações desenvolvidas na e pela escola. A sua direção é a formação de gerações futuras "éticas, solidárias, colaborativas e corresponsáveis" na construção de um mundo mais humano e democrático. Para isso, na qualidade de seres em formação, as crianças e os adolescentes devem ter suas necessidades amplamente supridas e uma formação que paute esses valores.

Por meio dos estudos realizados pelo GEPEJUC, compreende-se que o caminho da construção do currículo para os sujeitos do campo deve buscar as indagações da justiça nas três dimensões da justiça curricular: 1) A dimensão do conhecimento - que conhecimento interessa? A quem interessa? Interessa o conhecimento que vai fazer diferença para o aluno, para o professor, um conhecimento que construa a vida digna em todas as dimensões. É preciso questionar sempre como ele será construído para que proporcione aprendizagem para o educando. 2) A dimensão do cuidado - o cuidado na educação e na justiça curricular é fundamental, os seres humanos precisam ser cuidados. 3) A dimensão da convivência - uma escola tem de zelar para uma convivência democrática, por uma convivência não violenta, que não imprima a competitividade, que valorize a construção coletiva. Desse modo, busca-se o currículo que almeje a igualdade das dimensões apresentadas para que os sujeitos possam adquirir o conhecimento para compreensão do mundo e de si mesmos, do cuidado em todas as esferas do processo pedagógico. $\mathrm{O}$ intuito é possibilitar bem-estar nas suas áreas afetivas, cognitivas e físicas e de convivência com seus pares, proporcionada, de forma respeitosa, na escola (Ponce \& Neri, 2015).

O currículo escolar implica também 
a participação democrática e dos direitos humanos existentes dentro da comunidade escolar. Esse olhar expande-se quando efetivado com ações de cuidado, entendida como ausência de esquecimento, de reconhecimento, pela preocupação e o desvelo pelos outros, pela ética em benfeitoria de quem está em desvantagem (Estevão, 2004).

A legislação brasileira, assim como a concepção da justiça curricular, entende a escola como uma instituição cujos objetivos vão além da instrução. O seu compromisso com a construção da dignidade humana, com o cuidado, com a proteção dos sujeitos, é, portanto, fundamental. A justiça curricular propõe a reflexão cuidadosa sobre os desafios, de modo que possam ser superados, sugerindo, inclusive, que alunos e professores possam interagir, sentir-se bem, relacionar-se e aprender com essas interações. Significa proporcionar o intercâmbio de ideias, envolver os educandos em aprendizados argumentativos em relação aos seus direitos e aos seus deveres, além de “... desenvolver atitudes e padrões de pensamento construtivos; fazer escolhas, realizar projetos, comunicar suas ações, participar, dentro das possibilidades, das decisões que afetam sua vida ...". (Haddad, 2006, p. 532).
De acordo com os estudos realizados sobre o histórico da Educação do Campo, identifica-se que, desde seu início, as escolas do campo menosprezavam as especificidades sociais, culturais, econômicas, políticas e ambientais do mundo camponês. Atualmente, a organização do currículo das escolas do campo muitas vezes ainda nega o campo como espaço de produção cultural, econômica e política, entusiasmado pelo capitalismo que percebe os territórios rurais como espaço de atraso, de subdesenvolvimento e de improdutividade, desrespeitando as Diretrizes Operacionais para a Educação Básica nas Escolas do Campo (Resolução CNE/CEB No 1 , de 3 de abril de 2002). Essas Diretrizes visam um currículo que atenda às suas demandas, as quais se harmonizam com o conceito de justiça curricular e suas dimensões (Franco, 2018).

\section{O cenário da educação nas escolas do campo no Município de Humaitá (AM)}

O Amazonas, pela peculiaridade e pela configuração geográfica, suscita várias questões relacionadas às políticas e às práticas curriculares. Humaitá é um típico município ribeirinho do sul do Estado do Amazonas, conhecido como "A princesa do Madeira", por ter se tornado o centro mais importante do alto do Madeira, 
criado no contexto de colonização e de interesse econômico pela Amazônia (período áureo da borracha - década de 1890). O município está localizado à margem esquerda do Rio Madeira (segunda via de transporte mais importante da Amazônia, atrás apenas do Rio Amazonas), ao sul do estado do Amazonas, aproximadamente $697 \mathrm{~km}^{2} \mathrm{da}$ capital Manaus. Sua população é de 53.383 habitantes (Instituto Brasileiro de Geografia e Estatística [IBGE], 2017), sua área é de $33.071 .667 \mathrm{~km}^{2}$, um dos maiores em área territorial do estado.

A condição geográfica de Humaitá é marcada pela dinâmica social e econômica de fronteira. A população residente no interior do município está distribuída em pequenas comunidades que podem ser agrupadas em "polos" da área de terra firme (estradas) e da várzea do Rio Madeira. São cerca de 15 polos, cada um agrupando um certo número de comunidades e famílias. Os fluxos de pessoas e mercadorias entre a sede municipal e as comunidades ribeirinhas, bem como a comunicação, ocorrem quase sempre por via fluvial. $\mathrm{O}$ acesso às comunidades da terra firme e aquelas mais próximas da sede municipal geralmente dáse por via terrestre.

A Secretaria de Educação do Município de Humaitá (SEMED) é organizada por 3 coordenações pedagógicas: Coordenação da Área Urbana, Coordenação do Campo e Coordenação Indígena, estas agregam outros setores que dão suporte ao seu funcionamento. A partir da análise dos dados disponibilizados pela Coordenação do Campo (que envolve escolas ribeirinhas e da estrada) SEMED-Humaitá nos anos de $2015 / 2016 / 2017$, identificou-se que as 58 escolas localizadas no campo são distribuídas em polos, organizados de acordo com a distribuição geográfica das escolas. São 10 polos que atendem a diversas comunidades. Segundo Franco (2018, p. 30):

Essa divisão [envolve escolas ribeirinhas e da estrada] ocorre em função da logística de acesso. As escolas da estrada têm chegada mais fácil se compararmos às escolas da área ribeirinha. Entretanto, algumas escolas da estrada têm grandes dificuldades na estação chuvosa, conhecida como 'inverno amazônico', período caracterizado por grande volume de chuvas, o que dificulta a entrada às escolas devido às estradas não serem asfaltadas, e, assim, educadores e educandos enfrentam atoleiros. $\mathrm{Na}$ época do período seco (verão amazônico), o acesso é viável e a SEMED consegue atender mais facilmente a essas demandas. As escolas localizadas na área ribeirinha apresentam características bem diversas. Algumas estão localizadas ao longo do Rio Madeira e em igarapés próximos, o que possibilita o ingresso durante todo o ano letivo. Essas escolas são atendidas com frequência no abastecimento de 
produtos para a merenda escolar e material de consumo diversos. Outras escolas, no entanto, localizam-se dentro de pequenos rios, lagos e igarapés dificultando imensamente o acesso durante o período de vazante dos rios, pois, para se chegar a algumas escolas, é necessário viajar de lancha durante dias. Essa dificuldade reflete no atendimento direto das demandas dessas escolas.

Em 2015, eram 68 escolas, com 3.410 alunos matriculados, 139 professores e 14 gestores organizados em quatro polos. Em 2016, foram matriculados 3.300 alunos e havia 116 professores e 14 gestores, os estudantes encontravam-se divididos em 10 polos e 60 escolas. Em 2017, foram 58 escolas divididas em 10 polos. Cada polo possuía um supervisor, totalizando 172 professores, 14 gestores, 103 assistentes de serviços gerais (ASG) e 3.221 estudantes atendidos. Dos 186 professores/gestores, 121 possuíam contratos temporários, estabelecidos por meio de processo seletivo e 65 eram efetivos.

Das 58 escolas, em 2017, 13 funcionavam na modalidade de ensino seriado, uma em tempo integral e as demais, 45, eram multisseriadas. Dentre as escolas, apenas 14 tinham gestores, e, onde não havia gestor, um professor ficava responsável pela sua demanda.

A participação da coordenação do campo nas atividades sempre foi efetiva. Com relação aos professores e aos gestores, ocorreu uma oscilação no envolvimento nas atividades a cada ano. Em 2015, na pesquisa exploratória, em um universo de 153 sujeitos, compareceram aos encontros $43 \%$ dos professores e dos gestores. Em 2016, 70\% dos professores e dos gestores estavam presentes nos estudos e nas discussões, de um universo de 186 profissionais da educação. No último ano, 2017, dos 172 professores, 90\% participaram das atividades. Foram visitadas seis escolas dos Polos I, II, III, V, VI e $\mathrm{X}$ para que se efetivasse o contato direto com os estudantes, merendeiras e pais.

A partir do que foi vivenciado por meio da pesquisa participativa, utilizandose de pesquisa de campo, análise documental, entrevistas, momentos de reflexão-ação e da escuta sensível (Barbier, 2007), com os envolvidos, destacam-se, neste texto, evidências que conduzem a pensar que o currículo das escolas do campo carece de atendimento específico relacionado às necessidades da região.

\section{Atendimento às necessidades da região}

Os registros que serão apresentados a seguir estão relacionados às dificuldades encontradas pelos grupos de professores juntamente à Coordenação do Campo (SEMED) do município de Humaitá (AM) quanto ao atendimento da Educação do 
Campo: calendário escolar, transporte e merenda escolar.

A pesquisa revelou que o calendário escolar que conduziu as escolas localizadas no campo do município até o ano de 2016 era oriundo da área urbana, construído com base no modelo da Secretária Estadual de Educação e apenas pequenas mudanças aconteciam para atender ao município (áreas urbana e rural).

O suporte para que, no âmbito municipal, sejam realizadas as adaptações necessárias para a articulação com os tempos do campo está previsto na Lei de Diretrizes e Bases da Educação Nacional (LDB) $\mathrm{N}^{\mathrm{o}}$ 9.394, de 20 de dezembro de 1996, no art. 28: "Na oferta de educação básica para a população rural, os sistemas de ensino promoverão as adaptações necessárias à sua adequação às peculiaridades da vida rural e de cada região, especialmente", no inciso II, a “organização escolar própria, incluindo adequação do calendário escolar às fases do ciclo agrícola e às condições climáticas". A mesma preocupação está indicada nas Diretrizes Operacionais para a Educação Básica nas Escolas do Campo Resolução CNE/CEB No 1 , de 3 de abril de 2002:

Art. 7o É de responsabilidade dos respectivos sistemas de ensino, através de seus órgãos normativos, regulamentar específicas de atendimento escolar do campo e a flexibilização da organização do calendário escolar, salvaguardando, nos diversos espaços pedagógicos e tempos de aprendizagem, os princípios da política de igualdade. (Resolução $\mathrm{N}^{\mathrm{O}}$ 1, 2002, p. 32, ênfase dada).

A escola do campo atende estudantes que vivem da terra, que alternam os tempos de plantar e colher, e o tempo escolar, em muitos momentos, choca-se com o tempo do trabalho. As palavras utilizadas referem-se à adaptação, à flexibilização, à adequação do calendário, porém isso reporta novamente à questão do "ajuste dos serviços" da área urbana ao campo. Entende-se que a forma mais justa seria a criação de um calendário específico para as escolas do campo, que pondere e incorpore os diferentes sujeitos do campo e suas necessidades ao trabalho que realizam nesses espaços.

As comunidades ribeirinhas e da estrada, no município de Humaitá, vivem da caça, da pesca, da extração de minérios, do plantio. Todas essas atividades são realizadas pelos camponeses e seus familiares, envolvendo, na maioria dos casos, os filhos. Muitos deixam de ir à escola em determinadas situações para ajudar os pais. Assim,

... as formas de vinculação da infância à agricultura familiar exigem outras formas específicas de organização da escola. Não podemos transferir formas de organização da 
escola da cidade que partem de uma forma de viver a infância e a adolescência para as formas de viver a infância e a adolescência no campo. Precisamos das pesquisas sobre como se inserem a infância e a adolescência na organização camponesa, na agricultura familiar para articular a organização da escola, a organização dos seus tempos, aos tempos da infância, as formas de viver o tempo na própria infância. Há uma lógica temporal na produção camponesa que não é a lógica da indústria, nem da cidade. É a lógica da terra! É a lógica do tempo da natureza! É saber esperar e reinventar formas de intervir. A primeira coisa que o agricultor faz é olhar para o céu e para a terra. Esse é seu relógio! Plantar, não plantar; semear, não semear dependendo do tempo do céu e do tempo da terra. Essa lógica do tempo da natureza a qual ele sabiamente tem que se adaptar e sobre a qual terá que saber intervir traz coisas sérias para os tempos de escola. (Arroyo, 2006, p. 114-115).

Essas questões são perceptíveis na fala dos sujeitos envolvidos nas escolas: “ $A$ dificuldade também das escolas ribeirinhas é que, quando chega a época do garimpo, tem aquela evasão... nessa época agora (agosto - setembro), os alunos saem e vão embora" (Educadora B, 2016). "Às vezes eu falto na escola porque tenho que ajudar a família na roça" (Estudante B, 7ㅇan ano, 2016).

Os textos mostram com clareza a necessidade de articulação entre a atividade de produção e o calendário escolar, de forma que o currículo atenda às necessidades das comunidades ribeirinhas e às manifestações relevantes de sua cultura, beneficiando o processo de construção da identidade do campo e do conhecimento.

A relação escola/calendário escolar também é alterada por conta das características do clima da região, do transporte e do contrato dos professores. Os períodos de chuva intensa ou seca mudam o trajeto escolar e até impossibilitam o acesso à escola, resultando em faltas e o não cumprimento dos dias letivos como prevê a LDB $\mathrm{N}^{\mathrm{O}}$ 9.394/1996 (Art. 24), podendo adequar o calendário às peculiaridades locais, inclusive climáticas e econômicas, desde que cumpram a carga horária.

Em muitas escolas do município, os dias letivos são comprometidos em função da falta de combustível que abastece os motores dos transportes fluviais. A contratação, sem concurso público, de $65 \%$ dos professores (no ano de 2017) também inviabiliza o cumprimento dos dias letivos que ficam atrelados aos meses de março a novembro de cada ano. O calendário escolar precisa ser cumprido nesse espaço de tempo do contrato dos professores e demais funcionários.

Após um ano de atividades com os participantes da pesquisa, foram verificadas as possibilidades de criação de um calendário para as escolas do campo do 
município de Humaitá. Essa motivação partiu das reflexões realizadas com o grupo. Identificados os feriados, separados os dias necessários para o deslocamento dos professores até a cidade para receberem o pagamento e "fazerem $o$ rancho", reservados o dia para as atividades de formação e os demais itens que envolvem a elaboração do calendário. Todavia, o elemento mais significativo era o tempo da família, da colheita, da extração, do plantio e da colheita, do trabalho do camponês.

O fato de a contratação dos professores ocorrer sempre em fevereiro ou março atrasa o início das atividades, porém os dias registrados no calendário permaneceram, e o cumprimento do calendário escolar choca-se com questões administrativas.

As descrições podem ser ressaltadas pela leitura dos trechos: "se você pega o calendário, que é uma cópia da SEDUC, já está aqui o erro, você coloca que as aulas acabam dia 30 de novembro, mas antes disso já tem um outro dizendo que as aulas têm que terminar até o dia ... 14" (Educador F, 2017).

Há uma visão esclarecida por parte dos educadores no que diz respeito à temática. Eles têm consciência de que a questão dos dias letivos que não são cumpridos impede o desenvolvimento das atividades, sofrem em perceber que os estudantes são prejudicados e fazem tentativas para superar essa injustiça. Entretanto, o não cumprimento das políticas públicas impede que essas tentativas se efetivem com sucesso.

Outra temática em destaque é a relacionada ao transporte escolar. Estudantes, funcionários e educadores utilizam o transporte escolar, que é mantido pela Prefeitura do município e terceirizado por pessoas da região.

A existência de um número muito extenso de escolas, associada à dispersão de localização e ao atendimento reduzido do número de estudantes por instituição, tem levado os gestores públicos a adotar, como estratégia mais frequente, a política de nucleação dessas escolas vinculada ao transporte escolar, resultando no fechamento daquelas situadas nas pequenas comunidades rurais e na transferência dos estudantes para as localizadas em comunidades rurais mais populosas (sentido campo-campo) ou para a sede dos municípios (sentido campocidade). (Hage, 2011, p. 103).

A política de nucleação das escolas, associada à política de transporte escolar, gerou, em muitos lugares, estímulo ao fechamento das pequenas escolas, pois entende-se que os estudantes poderiam ser agrupados em escolas maiores (Hage, 2011; Munarim, 2006). No entanto, no que diz respeito à escola estar o mais próximo possível da residência do aluno, é um 
direito assegurado na Lei $\mathrm{N}^{\mathrm{o}}$ 8.069, de 13 de julho de 1990, inciso V, Art. 53, e reforçado no Plano Municipal de Educação (PME) de Humaitá - Lei no 688/2015 - na estratégia 9.2.9:

Reverter o fechamento das escolas do campo, retomando a ampliação da oferta educativa de qualidade para adolescentes, jovens e adultos, próximas aos locais de moradia, bem como assegurar a permanência das escolas do campo com recursos financeiros, humanos e valorização da identidade do campo. (Lei № 688, 2015, p. 71).

A nucleação das escolas pode ser identificada pela distribuição em polos. Um exemplo é o trajeto que as crianças fazem para chegar até a balsa escola, que leva em torno de 4 horas de barco, dependendo da estação. Muitas escolas foram extintas no decorrer dos anos em função de enchentes e do número de alunos. Estudantes deslocam-se da área rural e percorrem em torno de $45 \mathrm{~km}$ até a cidade para cursar o Ensino Fundamental e o Ensino Médio. A logística enfrentada para o deslocamento, a distribuição da frota e do combustível é bastante emaranhada, e, em decorrência disso, os estudantes, muitas vezes, são submetidos a longas horas de transporte cansativo e, algumas vezes, impróprio e sem coletes de proteção. Eles são transportados em ônibus, micro-ônibus, kombis, barcos, lanchas, rabetas, canoas, motos ou, até mesmo, vão de bicicleta, atravessando, por exemplo, igarapés.

Horários diferenciados de entrada e saída é uma das maneiras encontradas pelas escolas (segundo o relato dos gestores) para ajudar nesse tempo/horário deslocamento, na tentativa de favorecer a capacidade física e o aprendizado dos estudantes. Em algumas escolas, o início das aulas começa mais tarde para que os estudantes possam dormir um pouco mais e diminui-se o tempo do intervalo para que saiam mais cedo. Essa estratégia não pode ser utilizada em todas as escolas devido ao fato de os transportadores terem de buscar alunos no contraturno e a viagem de volta pode se estender até a noite, provocando riscos maiores durante o percurso.

A partir do ano de 2017, identificouse que a pontualidade na entrega do combustível para os transportadores e para as comunidades melhorou. Os contratos dos transportadores e o recebimento dos pagamentos foram regularizados, coincidindo com o pagamento dos educadores, evitando-se, dessa forma, que a escola estivesse pronta para retomar as atividades e o transportador ainda se encontrasse na cidade aguardando o pagamento - transportadores e educadores vão e voltam juntos. As demais demandas ainda aguardam providências. As empresas ainda ganham a licitação e os pequenos 
transportadores, que residem nas comunidades, em muitos casos, ficam subordinados a elas. Um novo caminho seria a definição de políticas que regulassem o transporte escolar a partir de critérios que priorizassem os serviços da própria comunidade onde as escolas estão inseridas.

Seria menos exaustivo, física e psicologicamente, para os alunos estudarem nas escolas do campo localizadas próximas às suas residências, de modo a respeitar suas particularidades, do que percorrerem longos trechos, pelos rios e pelas estradas, desde a madrugada, em diferentes tipos de transportes (muitas vezes em um mesmo trajeto: barco, a pé), cansados, em veículos que, em muitos casos, não oferecem a segurança e o cuidado necessários para seu bem-estar, fragilizando o processo educativo e $\mathrm{o}$ currículo escolar.

A merenda escolar também é fator de destaque. A demanda que a envolve se relaciona à qualidade/quantidade dos alimentos e ao cardápio oferecidos aos estudantes das escolas localizadas no campo. De onde vem os alimentos que chegam até as escolas do campo? Como eles são adquiridos?

Em 2016, o setor da merenda escolar foi composto por um coordenador de administração escolar, três nutricionistas (responsáveis técnicas - efetivas), uma assistente administrativa (efetiva), um motorista (área urbana) e um assistente de serviços gerais. A equipe é responsável pela distribuição da merenda para as escolas do município. Uma das nutricionistas explica que o Cardápio Escolar do Ensino Fundamental - Zona Rural e Indígena depende do orçamento que provém de recurso enviado pelo Programa Nacional de Alimentação Escolar (PNAE) $)^{\mathrm{i}}$, mais o recurso da Prefeitura. Justifica-se, no entanto, que o trabalho é realizado com previsão do orçamento e que o recurso que chega não é suficiente para atender a aproximadamente 9 mil alunos.

O setor deve adquirir os alimentos de acordo com o cardápio do programa de alimentação escolar, elaborados por nutricionistas capacitados, com a participação do Conselho de Alimentação Escolar (CAE) e respeitando os hábitos alimentares de cada localidade, sua capacidade agrícola e a preferência por produtos básicos e naturais (Oliveira, Santos, \& Oliveira, 2017).

As alocuções dos educadores, merendeiras e alunos evidenciam alguns apontamentos: "todas as verduras que vão para a merenda na cidade, a maioria sai da comunidade. Vem salsicha, conserva, já veio frango, charque, mas tiraram. Não 
tem fruta, nada" (Educadora E, 2016). Esse excerto refere-se ao fato de que os alimentos que são produzidos nas próprias comunidades são vendidos para os comerciantes na área urbana e não chegam até a cozinha da escola. A nutricionista explica sobre os alimentos produzidos pela comunidade: "para que os agricultores familiares possam entregar direto na escola, eles precisam estar registrados e participar da chamada pública". Ressalta, ainda, que, em 2017, seria melhor divulgado o edital de licitação da alimentação escolar e que havia uma nutricionista, junto ao Instituto de Desenvolvimento Agropecuário e Florestal Sustentável do Estado do Amazonas (IDAM), fazendo esse trabalho de divulgação nas comunidades.

O diálogo entre o setor da merenda e as escolas é conflituoso. Os educadores vão em busca de uma merenda saudável e o setor não tem como atender à demanda, de acordo com a nutricionista. Há dificuldade na distribuição: no quantitativo de pessoas que atendem ao setor e na distribuição dos recursos para que se forneçam os alimentos necessários e de que os estudantes gostam.

Pelas discussões ocorridas durante a pesquisa e por meio do caminho realizado na pesquisa exploratória ${ }^{\text {ii }}$, avalia-se que os alimentos podem levar de 7 a 11 dias para chegar nas comunidades, devido ao trajeto percorrido ao longo do rio. Entende-se que a má alimentação provoca a redução na atividade física, diminuição na capacidade de aprendizagem, baixa resistência às infecções e maior suscetibilidade a doenças. Os horários e a alimentação recebida nas escolas do campo do município podem promover essas dificuldades.

Este estudo entende que a articulação de projetos de educação ambiental e a produção de hortaliças, pensada em conjunto pela Secretaria de Educação e as escolas, além dos grupos de pesquisa das universidades do município e demais secretarias e organizações sociais, poderiam gerar a contribuição alimentar proveniente da própria comunidade. A Lei $n^{\circ} 11.947$, de 16 de junho de 2009, no Art. 14, institui, no mínimo, $30 \%$ dos recursos repassados pelo Fundo Nacional de Desenvolvimento da Educação (FNDE), no setor do Programa Nacional de Alimentação Escolar (PNAE), os quais deverão ser utilizados na aquisição de gêneros alimentícios diretamente da agricultura familiar. Esse é um recurso que ainda não foi explorado e pode ser encaminhado pela SEMED e comunidades, de forma a contribuir para garantir o direito das comunidades tradicionais de acesso regular e permanente a alimentos de 
qualidade, em quantidade suficiente, que respeitam a diversidade cultural.

O cuidado para que a merenda escolar adequada seja oferecida nas escolas pode contribuir expressivamente para uma vida saudável e um rendimento escolar satisfatório. As políticas públicas e o currículo devem corroborar para que os atores envolvidos - merendeiras, alunos, docentes - e todo o processo de distribuição contribuam para que esse objetivo seja atendido.

O calendário, o transporte e a merenda escolar são quesitos que se entrelaçam com o trabalho desenvolvido no "chão da escola" no município de Humaitá. São condições problematizadas e experienciadas por aqueles que fazem parte do currículo escolar do campo. Não se entende, neste texto, que a qualidade da escola seja inferiorizada por esse contexto, mas que esses pontos, se trabalhados, favorecerão o currículo, os tempos humanos e sua existência.

\section{Considerações finais}

É preciso pensar o currículo como uma vasta rede de significações, que envolve a escola e promove um espaço de construções coletivas. $\mathrm{O}$ currículo que não assegura o cumprimento dos direitos irá agravar a desigualdade e a injustiça. As situações apresentadas neste texto, com o objetivo de identificar, na realidade das escolas do campo do município de Humaitá, os seus limites e as suas possibilidades no atendimento às crianças da região tendo como parâmetro a dimensão do cuidado na busca da justiça curricular, podem produzir reflexões significativas para olhar o currículo escolar como um caminho a ser percorrido nas práticas de todos os atores envolvidos no processo de aprendizagem escolar, de vida, na possibilidade de uma escola que assegure o cuidado com o ser humano como uma dimensão da escola justa.

$\mathrm{Na}$ tentativa de contribuir com a justiça curricular, urgente, que minimize as inconsistências e as incoerências das políticas públicas nas escolas localizadas no campo do muncípio de Humaitá, faz-se necessário refletir sobre a concepção da justiça curricular, em especial a dimensão do cuidado, pois um ambiente democrático e acolhedor das diferenças ajuda a garantir e a consolidar a formação coletiva e solidária.

O cuidado com a justiça curricular deve levar em consideração as condições em que as escolas trabalham, os recursos materiais recebidos, a formação e os profissionais envolvidos, as particularidades das crianças e dos jovens que são atendidos, o contexto socioeconômico em que vivem, para que 
lhes seja possibilitado força para lutar por seus direitos de forma digna, protestando, se mobilizando para que possam melhorar sua história.

A dimensão do cuidado é imprescindível na construção das ações descritas anteriormente; no entanto, o que se observa na realidade vivenciada nas escolas localizadas no interior do Sul do Amazonas, no município de Humaitá, é que, entre o que está escrito e a prática curricular, existe uma distância muito grande, a injustiça curricular. Existem fatores problemáticos que impedem a concretização das práticas e da justiça curricular por meio desse olhar. Faz-se necessário refletir e conceber o currículo que privilegie o trabalho dos professores e educandos, pelo respeito aos seus "tempos humanos, mentais, culturais, éticos, socializadores, identitários, corpóreos ... especificidades de socialização, de aprendizagens, de formação: infâncias, pré-adolescência, adolescência, juventude, vida adulta". (Arroyo, 2010, p. 12).

O planejamento do poder público, o respeito aos direitos das populações do campo e o debate rigoroso e democrático sobre a educação no meio rural no município podem ser reforçados, com o intuito de perceber como o currículo escolar vem sendo definido e inserido. Além disso, é preciso compreender que a falta do cuidado com os aspectos levantados pela pesquisa em relação ao calendário, à merenda e ao transporte escolar poderiam ser minimizados e até mesmo resolvidos com o diálogo, a partir da promoção de um currículo com objetivos discutidos e almejados, de modo a modificar e a enriquecer o processo de construção do conhecimento, orientando e capacitando sujeitos.

A reprodução das diversas formas de desigualdades sociais apresentadas pela pesquisa compromete o devir da educação. O cuidado torna-se uma forma de reconhecimento, do olhar para o outro, de preocupação, de mobilização, que favorece as práticas cotidianas com os princípios da justiça social, do reconhecimento da diferença e da consolidação da justiça curricular. A base do cuidado humano é compreender como ajudar o outro a se desenvolver como ser humano.

\section{Referências}

Apple, M. W. (1989). Educação e poder. Porto Alegre: Artes Médicas.

Arroyo, M. G. (2006). A escola do campo e a pesquisa do campo: metas. In Molina, M. C. (Org.). Educação do Campo $e$ Pesquisa: questões para reflexão (pp. 103116). Brasília: Ministério do Desenvolvimento Agrário.

Arroyo, M. G. (2010). Escola: terra de direito. In Rocha, M. I. A., \& Hage, S. M. (Orgs.). Escola de direito: reinventando a 
escola multisseriada (pp. 9-12). Belo Horizonte: Autêntica.

Barbier, R. (2007). A pesquisa-ação. Tradução Lucie Didio. Brasília: Liber Livro.

Connell, R. W. (1995). Justiça, reconhecimento e currículo na educação contemporânea. In da Silva L. H., \& de Azevedo, J. C. (Orgs.). Reestruturação curricular: teoria e prática no cotidiano da escola (pp. 11-35). Petrópolis, Vozes.

Estêvão, C. V. (2004). Educação, justiça e democracia: um estudo sobre as geografias da justiça em educação. São Paulo: Cortez.

Franco, Z. G. E. (2018). Um olhar sobre as escolas localizadas no campo do Município de Humaitá (Sul do Amazonas): em busca da justiça curricular (Tese de Doutorado). Pontifícia Universidade Católica de São Paulo, São Paulo. Recuperado de http://bdtd.ibict.br/vufind/Record/PUC_SP -1 73835e36d4cbe3780e9722823bbe19c1

Freire, P. (1983). Educação como prática da liberdade. Rio de Janeiro: Paz e Terra.

Goodson, I. F. (1997). A construção social do currículo. Lisboa: Educa.

Haddad, L. (2006). Políticas integradas de educação e cuidado infantil: desafios, armadilhas e possibilidades. Cadernos de Pesquisa, 36(129), 519-546. Doi: http://dx.doi.org/10.1590/S0100$\underline{15742006000300002}$

Hage, S. A. M. (2011). Por uma escola do campo de qualidade social: transgredindo o paradigma (multi)seriado de ensino. Em Aberto, 24(85), 97-113.

Instituto Brasileiro de Geografia e Estatística. (2017). Humaitá: histórico. Recuperado em 31 out. 2017 de https://cidades.ibge.gov.br/brasil/am/humai ta/historico

Lei $N^{o}$ 688/2015. (2015). Plano Municipal de Educação - PME. Humaitá.

Lei $N^{o}$ 9.394, de 20 de dezembro de 1996. (1996). Estabelece as diretrizes e bases da Educação Nacional. Recuperado de http://www.planalto.gov.br/ccivil_03/LEIS /L9394.htm

Lei $N^{o}$ 8.069, de 13 de julho de 1990. (1990). Dispõe sobre o Estatuto da Criança e do Adolescente e dá outras providências. Recuperado de http://www.planalto.gov.br/ccivil_03/LEIS $\underline{\text { /L8069.htm }}$

Lei $n^{o}$ 11.947, de 16 de junho de 2009. (2009). Dispõe sobre o atendimento da alimentação escolar e do Programa Dinheiro Direto na Escola aos alunos da educação básica. Recuperado de http://www.planalto.gov.br/ccivil_03/_Ato 2007-2010/2009/Lei/L11947.htm

Lüdke, M., \& André, M. E. D. (1986). Pesquisa em Educação: abordagens qualitativas. São Paulo: EPU.

Munarim, A. (2006). Elementos para uma política pública de Educação do Campo. In Molina, M. C. (Org.). Educação do Campo e Pesquisa: questões para reflexão (pp. 1526). Brasília: Ministério do Desenvolvimento Agrário.

Oliveira, N. B., Santos, A. R., \& Oliveira, G. B. (2017, 26-28 abril). O Plano de Ações Articuladas e o Programa Nacional de Alimentação Escolar nas escolas. Artigo In Anais $28^{\circ}$ Simpósio Brasileiro de Política e Administração da Educação Estado, políticas e gestão da educação: tensões e agendas em (des)construção. João Pessoa, Paraíba.

Ponce, B. J., \& Neri, J. F. O. (2015). O currículo escolar em busca da justiça 
social: a violência doméstica contra criança e o adolescente. Revista e-Curriculum, 13(2), 331-349.

Resolução CNE/CEB $N^{o} 1$, de 3 de abril de 2002. Institui Diretrizes Operacionais para a Educação Básica nas Escolas do Campo. Recuperado de http://portal.mec.gov.br/index.php?option= com_docman\&view $=$ download\&alias $=138$ 00-rceb001-02-

pdf\&category_slug=agosto-2013pdf\&Itemid=30192

Severino, A. J. (2012). Educação, sujeito e história. São Paulo: Olho d'Água.

Thiollent, M. (2011). Metodologia da pesquisa-ação. 18 ed. São Paulo: Cortez.

Torres Santomé, J. (2013). Currículo escolar e justiça social: o cavalo de Troia da educação. Tradução Alexandre Salvaterra. Porto Alegre: Penso.

O PNAE, conhecido como Merenda Escolar, consiste na transferência de recursos financeiros do Governo Federal, em caráter suplementar, aos estados, Distrito Federal e municípios, para a aquisição de gêneros alimentícios destinados à merenda escolar - Lei n ${ }^{\circ}$ 11.947/2009 (Oliveira, Santos, \& Oliveira, 2017).

ii A pesquisa exploratória ocorreu no ano de 2015. A primeira fase tinha como objetivo identificar a realidade local. Em primeiro lugar, foi feito o contato com a SEMED do município, para solicitar a autorização para conhecer o seu funcionamento, identificar a organização do trabalho, o calendário escolar e o público atendido.

\author{
Informações do artigo / Article Information \\ Recebido em : 01/12/2018 \\ Aprovado em: 21/04/2019 \\ Publicado em: 28/05/2019 \\ Received on December 1st, 2018 \\ Accepted on April 21th, 2019 \\ Published on May, 28th, 2019
}

Contribuições no artigo: A autora foi responsável por todas as etapas e resultados da pesquisa, a saber: elaboração, análise e interpretação dos dados; escrita e revisão do conteúdo do manuscrito e; aprovação da versão final a ser publicada.

Author Contributions: The author was responsible for the designing, delineating, analyzing and interpreting the data, production of the manuscript, critical revision of the content and approval of the final version to be published.

Conflitos de interesse: A autora declarou não haver nenhum conflito de interesse referente a este artigo.

Conflict of Interest: None reported.

Orcid

Zilda Gláucia Elias Franco

http://orcid.org/0000-0003-1863-6309

\section{Como citar este artigo / How to cite this article}

APA

Franco, Z. G. E. (2019). Reflexões sobre a dimensão do cuidado na busca da justiça curricular das escolas do campo do município de Humaitá (AM). Rev. Bras. Educ. Camp., $4, \quad$ e6225. DOI: http://dx.doi.org/10.20873/uft.rbec.e6225

\section{ABNT}

FRANCO, Z. G. E. Reflexões sobre a dimensão do cuidado na busca da justiça curricular das escolas do campo do município de Humaitá (AM). Rev. Bras. Educ. Camp., Tocantinópolis, v. 4, e6225, 2019. DOI: http://dx.doi.org/10.20873/uft.rbec.e6225 